\title{
$\mathrm{R} C \& \mathrm{C}$
}

\section{INDICADORES DE LIQUIDEZ VERSUS MODELO DINÂMICO: APLICAÇÃO NO PERÍODO PRÉ E PÓS-CRISE NO SEGMENTO BANCOS}

\section{LIQUIDITY INDICATORS VERSUS DYNAMIC MODEL: APPLICATION IN PERIOD PRE AND POST- CRISIS BANKING SEGMENT}

Recebido em 29.01/2016 | Aceite final em 13.07.2016 |

Nota: este artigo foi aceito pelo Editor Jorge Eduardo Scarpin e passou por uma avaliação double blind

review

A reprodução dos artigos, total ou parcial, pode ser feita desde que citada a fonte.

\section{GLÁUCIA TEIXEIRA SANTOS}

Graduada em Controladoria e Finanças | Departamento de Ciências Contábeis| Universidade Federal de Minas Gerais - UFMG| Av. Antônio Carlos, 6627| Bairro Pampulha | CEP: 31270-901| Belo Horizonte/MG | Telefone: (31) 3409-7269 | Email:glauteixeira7@hotmail.com |

\section{JOSÉ ROBERTO DE SOUZA FRANCISCO}

Doutor em Administração/Finanças | Professor do Programa de Pós-Graduação em Contabilidade e Controladoria \& Finanças- CEPEAD/FACE/UFMG | Universidade Federal de Minas Gerais - UFMG| Av. Antônio Carlos, 6627| Bairro Pampulha | CEP: 31270-901| Belo Horizonte/MG | Telefone: (31) 3409-7269

Email:jroberto@face.ufmg.br|

\section{RESUMO}

Pesquisas mostram que o Brasil, diante da crise financeira de 2008, que assolou a economia mundial, conseguiu atravessar a turbulência criada neste contexto e as instituições financeiras bancárias se mantiveram relativamente sólidas durante esse período, sofrendo apenas pequenos impactos, quando observado empresas estrangeiras, que sofreram severamente, sendo algumas vendidas a preços irrisórios e outras declarando falência. Um item que pode explicar este fato é a boa gestão de recursos financeiros que os bancos brasileiros praticam, visando a liquidez nas suas operações. Na literatura, encontram-se duas técnicas de gestão financeira para a tomada de decisões: o modelo tradicional, utilizando indicadores de liquidez e o modelo dinâmico (Modelo Fleuriet). A fim de se verificar a solidez dos bancos brasileiros antes e após a crise, nesta pesquisa buscou-se analisar a qualidade da gestão financeira aplicando as duas técnicas citadas. A pesquisa apontou que as mudanças na gestão financeira, retração de crédito, alavancagem nas aplicações financeiras e, em títulos e valores mobiliários foram pontos que neutralizaram os impactos provocados pela crise financeira. Ressaltam-se as formas efetivas de atuação do Bacen quanto aos aspectos regulatórios de mitigação de riscos 
junto do sistema financeiro nacional, proporcionando liquidez, alavancagem operacional e estrutura de capital compatível com as necessidades exigidas pelo comportamento do mercado interno.

Palavras-chave: crise mundial; instituição financeira; modelo fleuriet.

\begin{abstract}
Research shows that Brazil, in the presence of the 2008 financial crisis that swept the world economy, got to cross the turbulence created in this context and the banking financial institutions have remained relatively strong during this period, suffering only minor impacts when observed foreign companies, which suffered severely, some being sold at derisive prices and other declaring bankruptcy. An item that can explain this fact is the good management of financial resources that Brazilian banks practice, aimed at liquidity in its operations. In the literature, there are two financial management techniques for decision-making: the traditional model, using liquidity indicators and the dynamic model (Model Fleuriet). In order to verify the fastness of Brazilian banks before and after the crisis, this study sought to analyze the quality of financial management by applying the two techniques cited. The survey demonstrated that changes in financial management, credit retraction, leverage the financial investments and marketable securities were points that neutralized the impacts caused by the financial crisis. Highlights the actual forms of the bacen acting as the regulatory aspects of risk mitigation with the national financial system, providing liquidity, operational leverage and capital structure consistent with the needs required by the behavior of the internal market.
\end{abstract}

Keywords: global crisis; financial institution; fleuriet model.

\title{
1. INTRODUÇÃO
}

Em 2010, a empresa de auditoria e consultoria Deloitte, publicou um livro intitulado As instituições financeiras no Brasil - O posicionamento em um novo cenário. Nesta obra, na qual vários profissionais renomados no setor financeiro do país deram suas contribuições, foram apresentados estudos e feitas análises de cenários para o mercado financeiro. Na perspectiva de Clodomir Félix F. C. Junior, na época líder da Deloitte no Brasil, o país conseguiu passar sem maiores dificuldades, se comparado a outros países, a turbulência dos mercados internacionais causada pela crise financeira mundial de 2008. As instituições financeiras brasileiras se mantiveram relativamente sólidas frente ao cenário global de instabilidade. Dentre os fatores que podem explicar esse fato, a competência em gerir bem as instituições é um dos principais. A função de intermediação financeira gera um risco específico para este tipo de instituição financeira, que é associado a sua própria atividade de intermediação financeira (HASTINGS, 2006).

Dado esse fato, as empresas do mercado financeiro devem ter uma boa gestão dos seus recursos financeiros para diluir esse risco. Para auxiliar esta gestão, além de auxiliar os diversos usuários das informações contábeis para diagnosticar problemas e realizar projeções, encontram-se na literatura duas técnicas de gestão financeira para o processo de tomada de decisão: o modelo tradicional, com o uso de índices de liquidez, e o modelo dinâmico de Fleuriet.

Revista de Contabilidade e Controladoria, ISSN 1984-6266

Universidade Federal do Paraná, Curitiba, v. 8, n.1, p. 08-22, mai./ago. 2016. 
Diante do contexto apresentado, surge como opção de pesquisa verificar a solidez dos bancos brasileiros no período pré e pós-crise financeira mundial de 2008, aplicando as duas técnicas de gestão financeira: modelo tradicional e modelo dinâmico de Fleuriet, buscando analisar a qualidade desta gestão.

O objetivo desta pesquisa é verificar a solidez dos bancos brasileiros durante o período pré e póscrise, abrangendo o período de 2006 a 2011, a partir do emprego de duas técnicas de gestão financeira descritas na literatura, sendo eles: modelo tradicional e modelo de Fleuriet, analisando a qualidade destas técnicas.

Este trabalho justifica-se pela importância da análise econômico-financeira do segmento bancos antes e após a crise de 2008 que afetou severamente as empresas ao redor do mundo, uma vez que isto oferece a oportunidade de identificar os impactos causados durante esse período, onde o cenário econômico era turbulento e as incertezas eram persistentes. Outro ponto a destacar é que as instituições financeiras têm como atividade principal de suas operações a intermediação financeira, que constitui um mecanismo de equilíbrio entre a captação e a liberação de recursos financeiros. Assim sendo, a liquidez financeira torna-se um relevante aspecto para a boa estabilidade, segurança e gerenciamento dessas instituições. Além disso, o estudo se justifica pela contribuição no desenvolvimento do conhecimento contábil pelo fato de poder auxiliar os diversos usuários das demonstrações contábeis a optar por técnicas de avaliação consistentes para o processo de tomada de decisão.

\section{FUNDAMENTAÇÃO}

\subsection{DEMONSTRAÇÕES CONTÁBEIS E SUA ANÁLISE}

Segundo SILVA (2013), a contabilidade é a linguagem dos negócios e as demonstrações contábeis são os canais de comunicação que nos fornecem dados e informações para diagnosticarmos o desempenho e a saúde financeira da empresa. Para MARQUES (2004), as demonstrações financeiras convencionais constituem a principal fonte de dados e/ou informações utilizadas para fins de avaliação de desempenho das empresas. As principais demonstrações contábeis são exposições sintéticas dos componentes patrimoniais e de suas variações, a elas recorremos quando desejamos conhecer os diferentes aspectos da situação patrimonial e suas variações (IUDíCIBUS et al., 2013). As informações contidas nas demonstrações financeiras são extremamente importantes para diversos grupos que necessitam regularmente construir medidas relativas da eficiência operacional da empresa (GITMAN, 2001).

Há nas empresas uma multiplicidade de fontes e usos da informação (IUDíCIBUS et al., 2013). Os gestores contábeis contribuem com a maior parte de sua atenção à coleta e à apresentação de dados financeiros. Já os Controllers enfatizam seus esforços na maximização do resultado e mitigação dos desperdícios financeiros. Os administradores financeiros avaliam as demonstrações contábeis, produzem dados adicionais e tomam decisões com bases nas suas avaliações entre risco e retorno. A informação contábil influencia o processo decisório de seus usuários afetando a alocação dos recursos e, em última análise, o funcionamento dos mercados (IUDíCIBUS, 1998). Uma organização é constantemente avaliada por usuários externos, como fornecedores, bancos e investidores, e essa é a causa primordial da obrigação das empresas em ter uma contabilidade idônea. (ASSAF NETO, 2012a). REVSINE, COLLINS \& JOHNSON (1998), citado por SANTOS E SANTOS (2008), discorrendo sobre a questão da análise financeira para fins de concessão de crédito, argumentam que um dos passos necessários neste processo é uma avaliação da qualidade dos demonstrativos contábeis. 
A Lei das Sociedades por ações (Lei no 6.404/76) estabelece no art. 176 que, ao final de cada exercício social, a diretoria deve elaborar as seguintes demonstrações financeiras: (i) balanço patrimonial, (ii) demonstração dos lucros e prejuízos acumulados, (iii) demonstração do resultado do exercício, (iv) demonstração do fluxo de caixa e (v) se companhia aberta, demonstração do valor adicionado. Para MATARAZZO (2010), a lei das S.A. representou notável avanço para efeito da análise de balanço, pois o conteúdo e a forma de apresentação das demonstrações financeiras atendem a necessidade da referida análise.

Historicamente, a análise financeira sempre esteve muito ligada à necessidade de identificação da solidez e do desempenho das empresas (SILVA, 2013). Segundo IUDíCIBUS (2009), foram os banqueiros os principais responsáveis pelo desenvolvimento da análise de balanços, pois, desde a segunda metade do século passado era prática relativamente comum a análise por parte dos bancos entre os valores a receber e a pagar das empresas para fins de determinação do risco de se conceder um empréstimo a mesma. A análise de balanços tornou-se praticamente obrigatória em 1915 nos Estados Unidos, porém, no Brasil, só se propagou nos anos 70.

SILVA (2013) define a análise financeira de uma empresa como um "exame minucioso dos dados financeiros disponíveis sobre a empresa, bem cômodas condições endógenas e exógenas que afetam financeiramente a empresa".

BRAGA (2012) relata que na literatura sobre análise são citados alguns métodos principais para o exame analítico das demonstrações contábeis, entre eles o método de análise por quocientes (índices ou ratios). Dentro desse método, esta pesquisa abordará duas técnicas: a análise tradicional e análise dinâmica (Modelo de Fleuriet), que serão explanadas nos tópicos seguintes.

\subsection{INSTITUIÇÕES FINANCEIRAS}

As instituições financeiras são classificadas, junto ao Sistema Financeiro Nacional (SFN), como elemento do subsistema operativo, cuja composição é formada pelas instituições bancárias (monetárias) e não bancárias (não monetárias) que atuam em operações de intermediação financeira.

Entende-se como principais funções dos intermediadores financeiros a liquidação de transações, custódia de excedentes, intermediação de recursos, captação de recursos e alocação (aplicação) dos mesmos (CAVALCANTI et. al., 2009).

As instituições financeiras estão sujeitas a um risco específico da sua própria atividade objeto, além daqueles comuns a toda atividade empresarial, que é o risco da intermediação financeira. Esta função principal gera um trabalho com níveis de alavancagem impensáveis comparados a outros tipos de empreendimentos (por exemplo, as empresas industriais raramente trabalham com alavancagem superior a proporção de 1:1, enquanto as instituições trabalham com recursos de terceiros 20 vezes maior do que seus recursos próprios). E há um agravante: os recursos de terceiros podem ser reclamados sem qualquer aviso prévio e para fazer frente a isso, as instituições financeiras devem manter recursos livres em caixa. Caso a instituição financeira não honre esses tipos de compromissos, boatos de baixa liquidez podem causar efeitos desastrosos no sistema financeiro, afetando outras instituições financeiras, o chamado "efeito dominó".

Portanto, esses recursos livres em caixa se constituem por meio da intermediação financeira e também do spread. FORTUNA (2013) define spread como "a diferença entre o custo do dinheiro tomado e o preço do dinheiro vendido, como, por exemplo, na forma de empréstimo."

ASSAF NETO (2012b) afirma: 
Esse diferencial de (taxas) spread descreve o desempenho econômico da instituição, enquanto o equilíbrio entre a liquidez dos elementos ativos e passivos reflete o objetivo da posição financeira. O sucesso na gestão dessas variáveis depende, essencialmente, da competência e do potencial do banco em negociar prazos e taxas de juros com os agentes, do nível de inadimplência de seus devedores, do comportamento de mercado e de eventuais garantias governamentais com relação à segurança e liquidez das instituições financeiras.

Deste modo, percebe-se a necessidade de uma eficiente gestão financeira de curto prazo por parte das referidas instituições. Dentro das técnicas existentes na literatura, este presente estudo destaca duas: a análise tradicional e a análise dinâmica (Modelo de Fleuriet).

\subsection{ANÁLISE TRADICIONAL}

Segundo KASSAI (2002), "Além de informações específicas, disponíveis diretamente nas demonstrações, os usuários buscam indicadores que as relacionem. São diversos os indicadores de análise já consagrados pelo uso e infinitas as possibilidades de criação de novos índices que espelhem a experiência do analista ou do tomador de decisão".

A análise de gestão financeira tradicional é feita através do uso de indicadores para se avaliar o equilíbrio, eficiência e solidez empresarial. Segundo MATARAZZO (2010), os índices constituem a técnica de análise mais empregada e eles representam a relação entre contas ou grupo de contas das Demonstrações Financeiras, que visa evidenciar determinado aspecto da situação econômicofinanceira de uma empresa ou ainda, para SANTOS, RENGEL e HEIN (2009), medir os níveis de desempenho da organização.

Segundo MARQUES (2004), as medidas de avaliação de desempenho, também conhecidas por índices, se agrupam em geral em quatro diferentes categorias, de acordo com seus respectivos objetivos de análise: (a) quocientes de liquidez e solvência; (b) de estrutura e endividamento; (c) de rotação e (d) de rentabilidade e lucratividade. Os conceitos de solvência e liquidez são intimamente relacionados e tratados como sinônimos na literatura (CRUZ, 2011). Neste presente trabalho, serão abordados os índices de liquidez, no sentido de realizar um paralelo com a Análise Dinâmica.

COSTA et. al. (2008), citado por CRUZ (2011), afirma que ter boa situação econômico-financeira é quando a empresa apresenta adequado equilíbrio entre a sua liquidez e a sua rentabilidade. Para SANTOS E SANTOS (2008), "as definições do termo liquidez encontradas na literatura geralmente remetem à ideia de capacidade de pagamento, sendo que as medidas (ou indicadores) dessa capacidade de pagamento são obtidas pela comparação entre os ativos circulantes (direitos realizáveis) e os passivos circulantes (exigibilidades)." Segundo IUDícIBUS et.al. (2013), um dos tópicos a ser enfocado no Relatório da Administração da empresa é a análise da posição financeira, que envolve a situação de liquidez. A avaliação dos índices de liquidez é de suma importância, já que a correta interpretação de seus resultados fornece base necessária para uma análise adequada da situação financeira da empresa.

Na literatura, encontram-se quatro principais índices de liquidez, que são:

i. Índice de Liquidez Geral (ILG): esse indicador revela a liquidez, tanto de curto como de longo prazo. É utilizada também como uma medida de segurança financeira da empresa a longo prazo, revelando, assim, sua capacidade de saldar todos seus compromissos (ASSAF NETO, 2012b);

ii. Índice de Liquidez Corrente (ILC): indica a solidez do embasamento financeiro da empresa frente aos seus compromissos de curto prazo. Expressa quantas vezes os ativos circulantes de uma empresa "cobrem" os passivos circulantes (BLATT, 2001); 
iii. Índice de Liquidez Seca (ILS): GITMAN (2001) define o índice de liquidez seca é semelhante ao índice de liquidez corrente, excluindo-se, porém, a conta estoques, que geralmente são os ativos circulantes menos líquidos de todos. A baixa resulta basicamente de dois fatores:

(i) Muitos tipos de estoques não podem ser vendidos com facilidade porque são itens parcialmente acabados e/ou têm finalidades específicas; (ii) o produto estocado é normalmente vendido a prazo, o que significa que se transforma em contas a receber antes de ser convertido em caixa (GITMAN, 2001);

iv. Índice de Liquidez Imediata (ILI): mede a capacidade de pagamento de curtíssimo prazo. De acordo com ASSAF NETO (2012c),

Reflete a porcentagem das dívidas de curto prazo (passivo circulante) que pode ser saldada imediatamente pela empresa, por suas disponibilidades de caixa. Evidentemente, quanto maior se apresentar esse índice, maiores serão os recursos disponíveis mantidos pela empresa.

Para MATARAZZO (2010), o importante não é o cálculo de grande número de índices, mas de um conjunto de índices que permita conhecer a situação da empresa, segundo o grau de profundidade desejada da análise. Porém, um índice isolado não consegue fornecer informação suficiente sobre o desempenho geral da empresa. Julgamentos razoáveis só podem ser feitos quando se usa um grupo de índices. Se uma análise estiver voltada para algum aspecto específico da posição financeira de uma empresa, entretanto, um ou dois índices talvez sejam suficientes (GITMAN, 2001). O enfoque segundo o qual a análise das demonstrações financeiras é desenvolvida pode variar conforme o interesse do analista (ASSAF NETO, 2012c).

FLEURIET, KEHDY, BLANC $(2003, p .78)$ destacam que a análise dos índices de liquidez é o método mais frequentemente adotado pelos bancos, mas alerta que ela é insuficiente, e às vezes perigosa. Os autores chamam atenção para os três pontos a seguir:

1) A utilização do método dos índices financeiros pressupõe a utilização de índices financeiros de referência. [...] O problema maior envolvendo a determinação de índices que possam ser considerados 'ideais'.2) Os índices financeiros são calculados tomando-se como base a situação presente ou passada, mas não fazem nenhuma indicação sobre a situação futura da empresa. [...] 3) Este método também não é adequado para as análises a longo prazo. Convém observar que é muito difícil fazer uma previsão da literatura da empresa para um período de cindo anos. [...]

O método tradicional de análise financeira das empresas, quando baseada somente no Balanço Patrimonial, possui uma visão estática, incompatível com o dinamismo do cotidiano empresarial (FLEURIET; KEHDY; BLANC, 2003). Assim, os analistas podem utilizar modelos mais dinâmicos e analíticos, além das técnicas tradicionais de análise econômico-financeira, tal como o modelo do capital de giro, o qual é abordado a seguir.

\subsection{MODELO DINÂMICO}

O modelo Fleuriet foi introduzido no ano de 1977, pelo professor Michel Fleuriet e pela Fundação Dom Cabral, com a publicação da obra O Modelo Fleuriet - A dinâmica financeira das empresas brasileiras, sendo um marco divisório na gestão da liquidez, trazendo grande contribuição para a melhora da gestão financeira das empresas. 
Primeiramente, foi proposta uma reclassificação das contas do Balanço Patrimonial. A classificação tradicional se revela inadequada para fins de uma análise dinâmica da situação econômico-financeira das empresas (FLEURIET, KEHDY, BLANC, 2003). Certas contas apresentam movimentação lenta em uma análise de curto prazo, podendo dessa forma, ser classificada como permanente ou não cíclicas. $\mathrm{E}$ há contas que acompanham o ciclo operacional da empresa, mantendo-se em constante movimento cíclico e contínuo (MACHADO et. al., 2005). Este fato justifica uma nova classificação horizontal, que irá refletir os verdadeiros ciclos econômico e financeiro de uma empresa, fornecendo dados diferentes aos obtidos a uma análise estática que se utiliza do Balanço Patrimonial Tradicional (FLEURIET, KEHDY, BLANC, 2003). Assim, as contas do ativo e passivo são reclassificadas como mostra a Figura 1.

Figura 1 Reclassificação das contas do Balanço Patrimonial

\begin{tabular}{|c|c|l|}
\hline Contas & Classificação & \multicolumn{1}{c|}{ Definição } \\
\hline $\begin{array}{c}\text { Ativos e Passivos } \\
\text { Circulantes }\end{array}$ & Contas Erráticas & $\begin{array}{l}\text { São contas de curto prazo não necessariamente renováveis ou } \\
\text { ligadas à atividade operacional da empresa. }\end{array}$ \\
\cline { 2 - 3 } & Contas cíclicas & $\begin{array}{l}\text { São contas de curto prazo, renováveis e ligadas a atividade da } \\
\text { empresa. São conhecidas como cíclicas por girarem muito } \\
\text { rápido. }\end{array}$ \\
\hline $\begin{array}{c}\text { Ativos e Passivos não } \\
\text { circulantes }\end{array}$ & $\begin{array}{c}\text { Contas não } \\
\text { cíclicas }\end{array}$ & $\begin{array}{l}\text { São contas que apresentam aplicações por prazo superior a um } \\
\text { ano. }\end{array}$ \\
\hline
\end{tabular}

Fonte: Dados da pesquisa, 2013.

De acordo com MACHADO et. al. (2005), baseado nessa reclassificação do Balanço Patrimonial, o modelo Fleuriet propõe o cálculo de três variáveis usadas na análise dinâmica. Essas variáveis permitem aos usuários das informações financeiras interpretarem as decisões dos gestores, além de identificar suas consequências e fazer previsões sobre o futuro da empresa (MONTEIRO, 2003). As três variáveis são: Necessidade de Capital de Giro (NCG), Capital de Giro (CDG) e Saldo de Tesouraria (ST). Além destas variáveis, a divisão do Capital de Giro (CDG) pela Necessidade de Capital de Giro (NCG) nos fornece o cálculo do chamado Termômetro de Liquidez ou Índice de Liquidez do Modelo Dinâmico (ILD), auxiliando na análise de liquidez de curto prazo (FRANCISCO et. al., 2010).

O CDG é representado pelos recursos necessários pela empresa para financiar as suas atividades operacionais. A forma mais direta de se obtê-lo é pela simples diferença entre os passivos não cíclicos e os ativos não cíclicos (ASSAF NETO, 2012c). O Capital de Giro normalmente apresenta-se estável ao longo do tempo, a não ser quando a empresa realiza novas aplicações em bens do ativo permanente. Porém, esses investimentos, em geral, são realizados por meio de empréstimos de longo prazo e novos aportes de capital, que por sua vez aumentam o Capital de Giro, compensando a redução causada por esses investimentos. Se a empresa souber administrar o CDG, ela terá bons resultados até com baixa liquidez ou resultado negativo, pois conseguirá prever com maior grau de certeza as suas entradas de caixa (FLEURIET, KEHDY, BLANC, 2003).

A NCG, Segundo (FLEURIET, KEHDY, BLANC, 2003), é um conceito econômico e não uma definição "legal". Para MATARAZZO (2010), "a NCG é a chave a administração financeira de uma empresa", sendo importante também do ponto de vista de financiamento, crescimento e lucratividade. É dada pela diferença entre as contas cíclicas do ativo e as contas cíclicas do passivo. Quando as entradas de caixa ocorrem depois das saídas de caixa, temos uma NCG positiva, ou seja, uma aplicação permanente de fundos

O ST é definido como a diferença entre ativo errático e passivo errático ou o valor residual dado pela diferença entre CDG e NCG. Portanto, caso o CDG seja insuficiente para financiar a NCG, essa diferença será um valor negativo, representando um agravante por aumentar seu risco de insolvência, pois indica que a empresa financia uma parte da NCG com recursos de curto prazo. Por 
outro lado, ter o ST positivo não necessariamente pode ser um bom indicador. A empresa pode estar deixando de aproveitar oportunidades de aplicações, como em títulos de liquidez imediata (Open Market), enquanto o dinheiro fica parado, seja por falta de estratégia de investimento ou outro motivo qualquer.

Por fim, o ILD, segundo GITMAN (2000), também conhecido como Índice do Modelo Dinâmico, é medido pela relação entre o ST e NCG. Assim, o ILD mede a relação do fluxo líquido do dinheiro ST com o fluxo líquido da atividade operacional NCG. Através dele é possível verificar liquidez da empresa e saber o quanto a empresa precisa captar para suprir sua necessidade financeira.

FLEURIET, KEHDY e BLANC (2003) definem alguns perfis financeiros para as empresas de acordo com os resultados das variáveis estabelecidas no Modelo Dinâmico:

i. SÓLIDA: para os autores, uma empresa para ser caracterizada como sólida financeiramente, ela deve apresentar ST positivo assim com a sua NCG. Essa situação permite que a empresa enfrente aumentos temporários da NCG. Além disso, o CDG deve apresentar um valor negativo;

ii. INSATISFATÓRIA: uma empresa dita em situação insatisfatória deve apresentar CDG e NCG positivos e ST negativo. Trata-se de uma empresa que luta por sua sobrevivência, pois apresenta risco de insolvência alto, financiando suas aplicações permanentes com fundos de curto prazo;

iii. ALTO RISCO: situação financeira de alto risco corresponde a ter em sua estrutura inversa do perfil de empresa dita insatisfatória. A maioria das empresas que apresenta balanços deste tipo dedica-se à distribuição de mercadorias que são vendidas à vista e adquiridas a prazo;

iv. EXCELENTE: ser excelente significa ter CDG positivo assim como o ST, e não ter NCG, ou seja, apresentar valor negativo para esta variável. Trata-se de um perfil relativamente difícil de estabelecer, pois indica que a empresa possui recursos de sobra para serem aplicados no mercado ou em suas atividades, situação essa rara no mercado.

\section{METODOLOGIA}

\subsection{TIPO DE PESQUISA}

A pesquisa aqui desenvolvida classifica-se como descritiva por apenas observar os fatos sobre a análise da gestão financeira dos bancos brasileiros, registrá-los, analisá-los, classificá-los e interpretálos, sem interferência do autor. Assim, os fenômenos do mundo físico e humano são estudados, mas não são manipulados pelo pesquisador (ANDRADE, 2008, citado por BEUREN et. al. (2009, p. 81)).

\subsection{AMOSTRA E FONTE DE DADOS}

Referente à população-alvo objeto desta pesquisa, optou-se por uma amostragem não probabilística do tipo intencional. As empresas investigadas foram as Instituições Financeiras de capital aberto, extraídas do site da BM\&FBOVESPA, que tivessem como classificação o setor "Bancos" subsetor "Intermediários Financeiros". Ainda como requisito para compor a amostra, optou-se pelas empresas que estão listadas nos níveis de Governança Corporativa da BM\&FBOVESPA; desta forma, do total de 27 empresas, foram excluídas 13 empresas da amostra. A amostra final foi selecionada por empresas do setor "Bancos" da BM\&FBOVESPA que estão listadas em algum nível de Governança Corporativa. No final, a amostra totalizou 14 empresas do setor "Bancos".

Após definida a amostra, foram coletadas as Demonstrações Financeiras das empresas selecionadas referente aos anos de 2006 a 2011 para cálculo das variáveis dos índices do modelo tradicional e das variáveis do modelo dinâmico. Os indicadores financeiros tradicionais calculados foram: liquidez 
geral, liquidez corrente, liquidez seca e liquidez imediata. Optou-se por estes indicadores por se entender que são estes os que possuem a mesma finalidade da análise dos indicadores dinâmicos (Fleuriet) relacionados ao capital de giro e à liquidez da empresa. Em seguida, os balanços coletados foram reclassificados conforme modelo preconizado por Fleuriet, e obtiveram-se as variáveis CDG, ST, NCG e o ILD, todos do Modelo de Fleuriet. Foram calculadas médias para todos os anos estudados, e calculadas médias para o período pré-crise e período pós-crise de cada variável.

Posteriormente, os índices do modelo tradicional foram comparados com as variáveis do modelo dinâmico e analisados para verificar se havia divergências entre a análise de gestão financeira das empresas analisadas, segundo o modelo de análise adotado.

\section{RESULTADOS}

Iniciou-se o presente estudo segregando o período de análise entre pré-crise financeira e pós crise financeira, a saber: pré-crise, contendo os anos de 2006, 2007 e 2008, e pós-crise, contendo os anos de 2009, 2010 e 2011, assim, contemplando o período da pesquisa.

Em relação a período pré-crise (2006, 2007 e 2008), parte-se da análise dos resultados obtidos pelo cálculo dos índices de liquidez descritos no modelo tradicional, sejam eles: liquidez geral, liquidez imediata, liquidez corrente e liquidez seca, e análise dos resultados obtidos na aplicação do modelo dinâmico, ambos para o período pré-crise. Foi calculada média aritmética para cada ano e para o período, assim como mostra a Tabela 1.

Tabela 1 Médias aritméticas anuais e para o período pré-crise dos indicadores do modelo tradicional

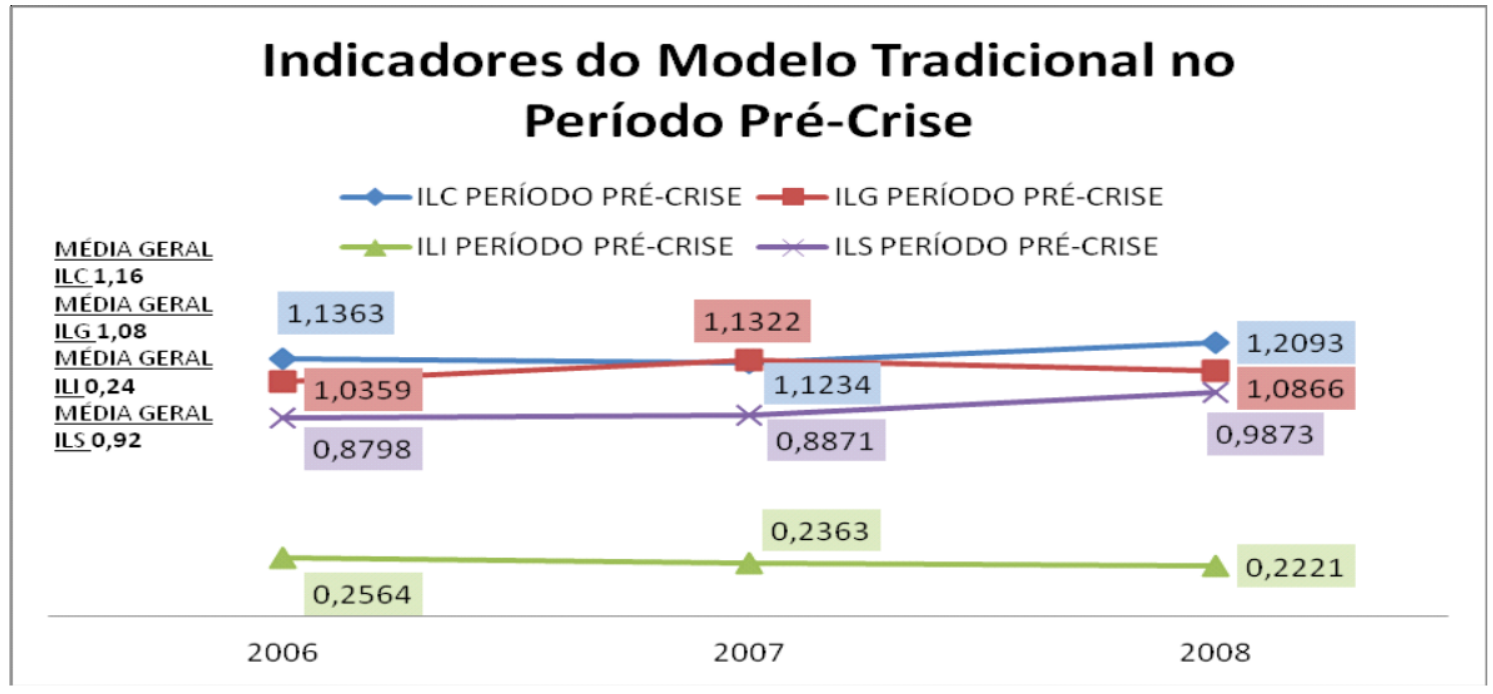

Fonte: Dados da pesquisa, 2013.

A partir dos resultados obtidos por meio da Tabela 1, pode-se inferir uma avaliação sobre solidez dos bancos através da sua gestão financeira. Partindo primeiramente da análise dos resultados dos indicadores do Modelo Tradicional, pode-se perceber que ao longo do período analisado, as empresas brasileiras do setor Bancos mostraram uma boa estrutura de liquidez e solvência no período pré-crise mantendo, relativamente, um mesmo nível de liquidez, sem variações significativas. Percebe-se que a curtíssimo prazo, ou seja, quando se fala de Liquidez Imediata, as empresas possuem certa dificuldade de honrar seus compromissos, apresentando uma média geral bastante inferior a 1, como indica a Tabela 1. Este índice apresentou seu menor valor, na média, nos ano de 2008, no valor de 0,2221 , no auge da crise, mostrando um impacto imediato.

Revista de Contabilidade e Controladoria, ISSN 1984-6266

Universidade Federal do Paraná, Curitiba, v. 8, n.2, p. 08-22, mai./ago. 2016. 
Algo semelhante acontece com o índice de Liquidez Seca que, apesar de apresentar um desempenho satisfatório no período, ou seja, próximo de 1, conforme Tabela 1, reforça o fato das empresas do setor Bancos possuírem certa dificuldade em sua capacidade de honrar seus compromissos no curtíssimo prazo, corroborando com o resultado encontrado para a Liquidez Imediata.

À medida que é concedido prazo nas estruturas patrimoniais, os índices de liquidez apresentam resultados mais favoráveis, onde se destacou o índice de Liquidez Geral e o índice de Liquidez Corrente que, na média, alcançaram um valor de 1,08 e 1,16 (Tabela 1), respectivamente. Cabe destacar que ambos os índices apresentaram seu maior valor, dentro do período pré-crise, em 2008, no ano da crise. Portanto, no geral, pode-se afirmar que as empresas possuem boa capacidade de pagamento tanto no curto quanto no longo prazo, demonstrando a boa gestão dos seus recursos financeiros.

Os bancos têm como matéria-prima para a utilização nas suas atividades operacionais os recursos financeiros; portanto, quanto maior aplicação desses recursos, melhor gestão financeira por parte das empresas, motivo pelo qual se justifica a escassez de recursos financeiros a curtíssimo prazo e uma melhora financeira a curto prazo.

Após análise do modelo tradicional, parte-se para a análise das variáveis do Modelo Dinâmico, quais sejam: NCG, CDG, ST e o ILD, analisados por meio da Tabela 2.

Tabela 2 Médias aritméticas anuais e para o período pré-crise das variáveis do modelo dinâmico

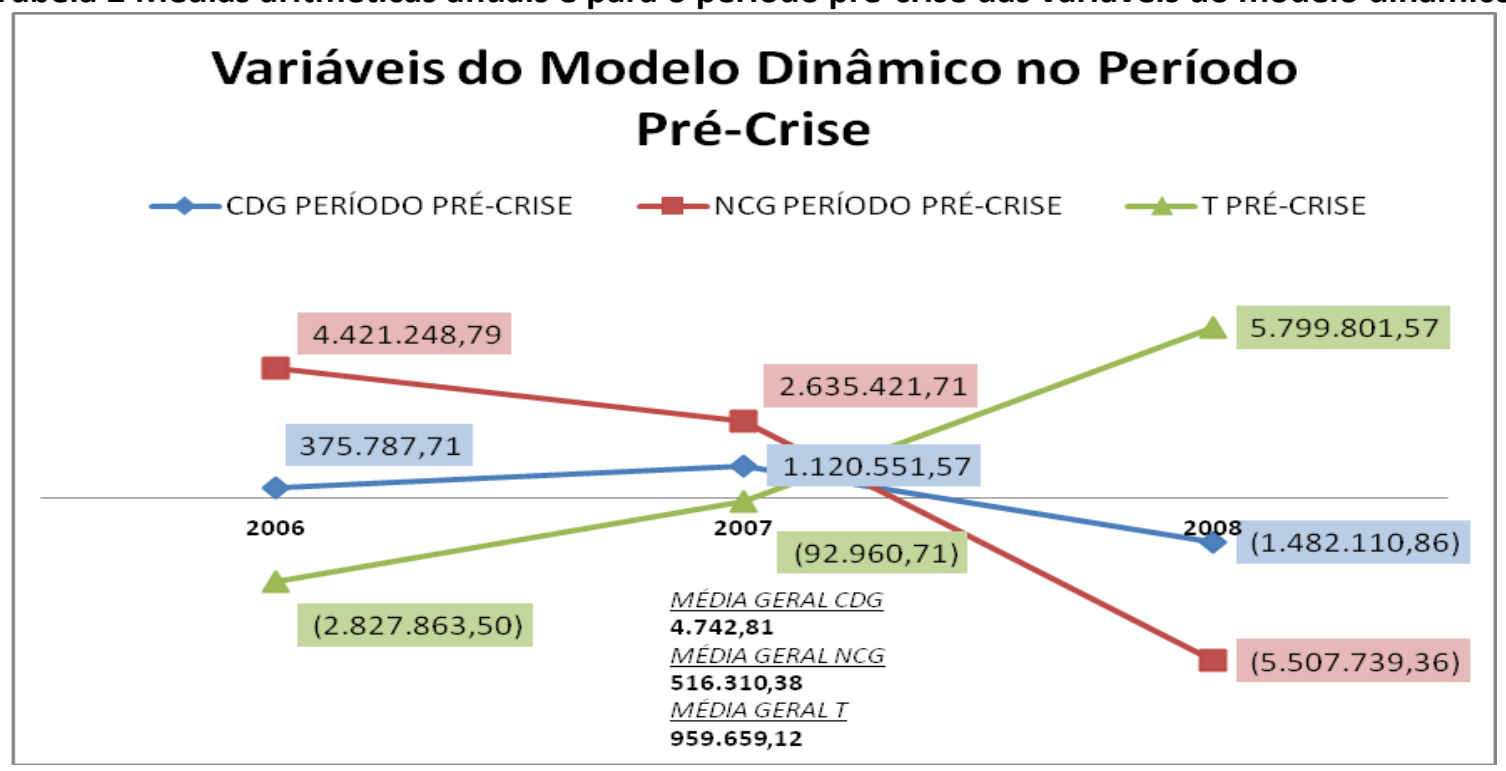

Fonte: Dados da pesquisa, 2013.

Por meio da Tabela 2, verifica-se a configuração de uma estrutura típica de empresas com perfil financeiro sólido, onde as empresas apresentam balanços que se configuram com: CDG, NCD e T positivos, quando analisamos a média geral obtida para o período pré-crise. Ao analisar cada ano individualmente, nota-se uma trajetória descendente, ou seja, uma tendência de piora, pois em 2006 e 2007 os bancos apresentavam um perfil financeiro insatisfatório, sendo que em 2008 essa situação se agravou, rebaixando-os para um perfil financeiro de alto risco. Este fato é condizente com a situação de crise que foi se instalando no mercado financeiro, até o seu auge em 2008.

O crescimento exponencial do ST pode ser relacionado às incertezas quanto a se investir em um período turbulento, sendo muito arriscado aplicar recursos em um momento de instabilidade, forçando os bancos a manterem estes recursos em caixa. 
Ao se observar sob o ponto de vista do modelo Fleuriet, verifca-se a Tabela 3 o movimento do ILD.

Tabela 3 Variável ILD para o período pré-crise

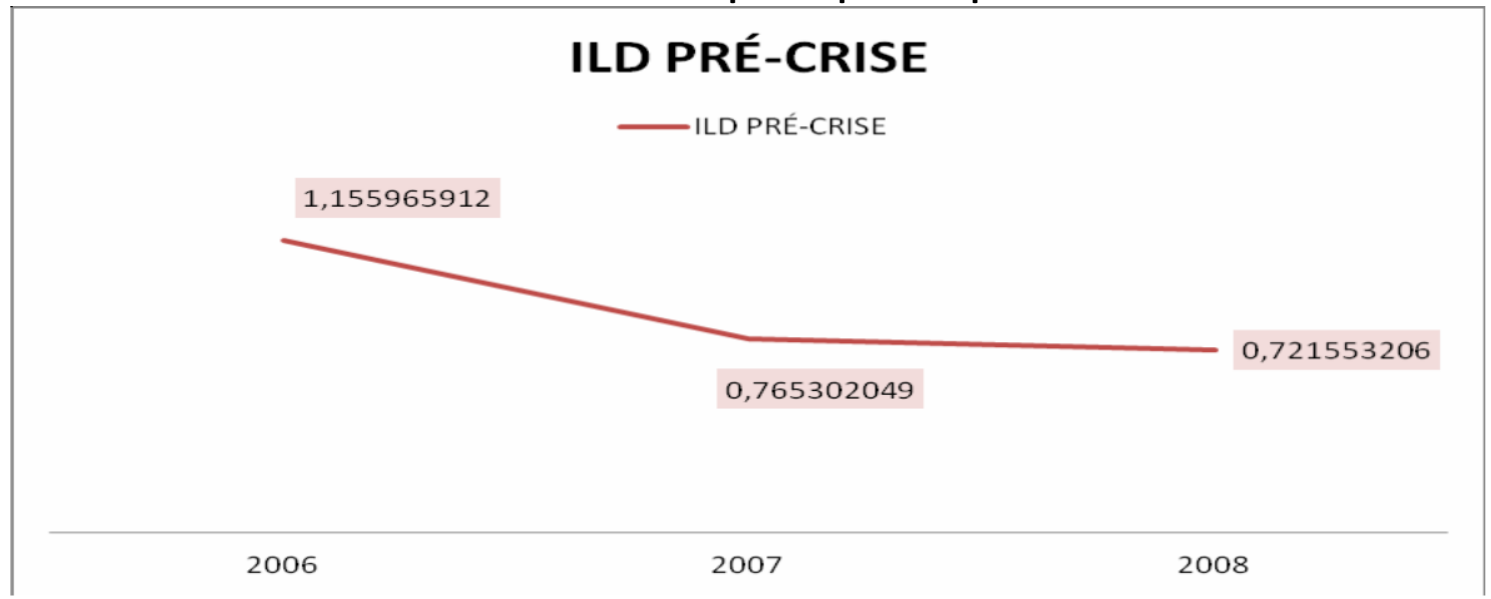

Fonte: Dados da pesquisa, 2013.

Observa-se que no período pré-crise por meio do ILD uma retração da capacidade de geração de recursos por parte das instituições financeiras no segmento banco. Tal fato apontou um decréscimo de $38 \%$ da capacidade gestão de recursos financeiros.

Em relação a período pós-crise (2009, 2010 e 2011), parte-se da análise dos resultados obtidos pelo cálculo dos índices de liquidez descritos no modelo tradicional, sejam eles: liquidez geral, liquidez imediata, liquidez corrente e liquidez seca, e análise dos resultados obtidos na aplicação do modelo dinâmico, ambos para o período pós-crise. Foi calculada média aritmética para cada ano e para o período, assim como mostra a Tabela 4.

Tabela 4 Médias aritméticas anuais e para o período pós-crise dos indicadores do modelo tradicional

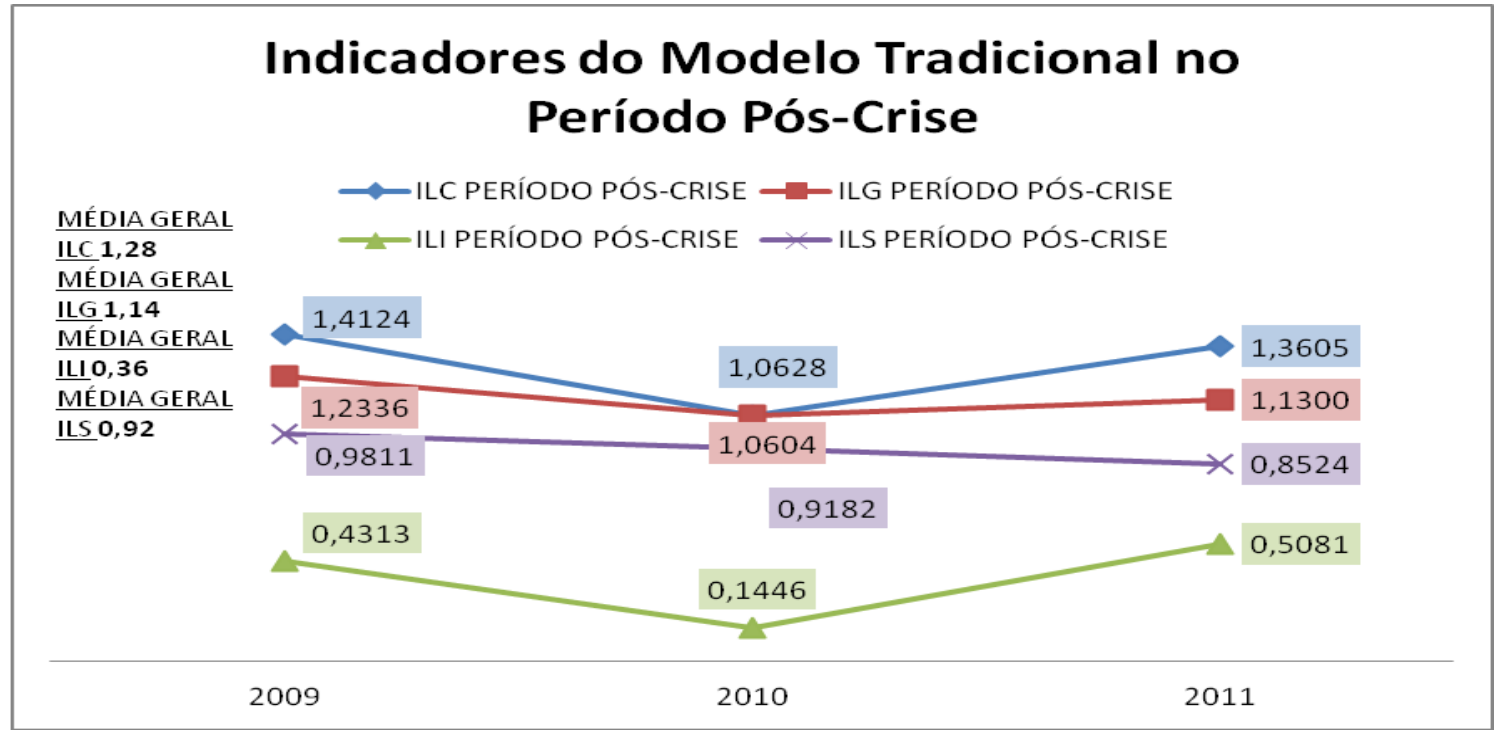

Fonte: Dados da pesquisa, 2013.

Conforme se observa pelos resultados obtidos para o Modelo Tradicional, indicados na Tabela 4, os indicadores de liquidez apresentaram melhoria, a exceção do índice de Liquidez Seca, que se manteve estável. Isso significa que a boa gestão dos bancos brasileiros em detrimento a estrutura financeira e patrimonial foi suficiente para que as instituições financeiras analisadas não tivessem escassez de recursos financeiros. 
Fator relevante pode ser observado no ano de 2010, onde o Banco Central do Brasil editou algumas normas de regulação junto ao sistema financeiro nacional de forma a normatizar as atividades operacionais de posse a manter maior estrutura operacional, liquidez e segurança das operações financeiras, principalmente voltadas para a adequação do Acordo de Basiléia III.

Já no que tange a análise do Modelo Dinâmico foi verificado por meio da Tabela 5, conforme abaixo.

Tabela 5 Médias aritméticas anuais e para o período pré-crise das variáveis do modelo dinâmico

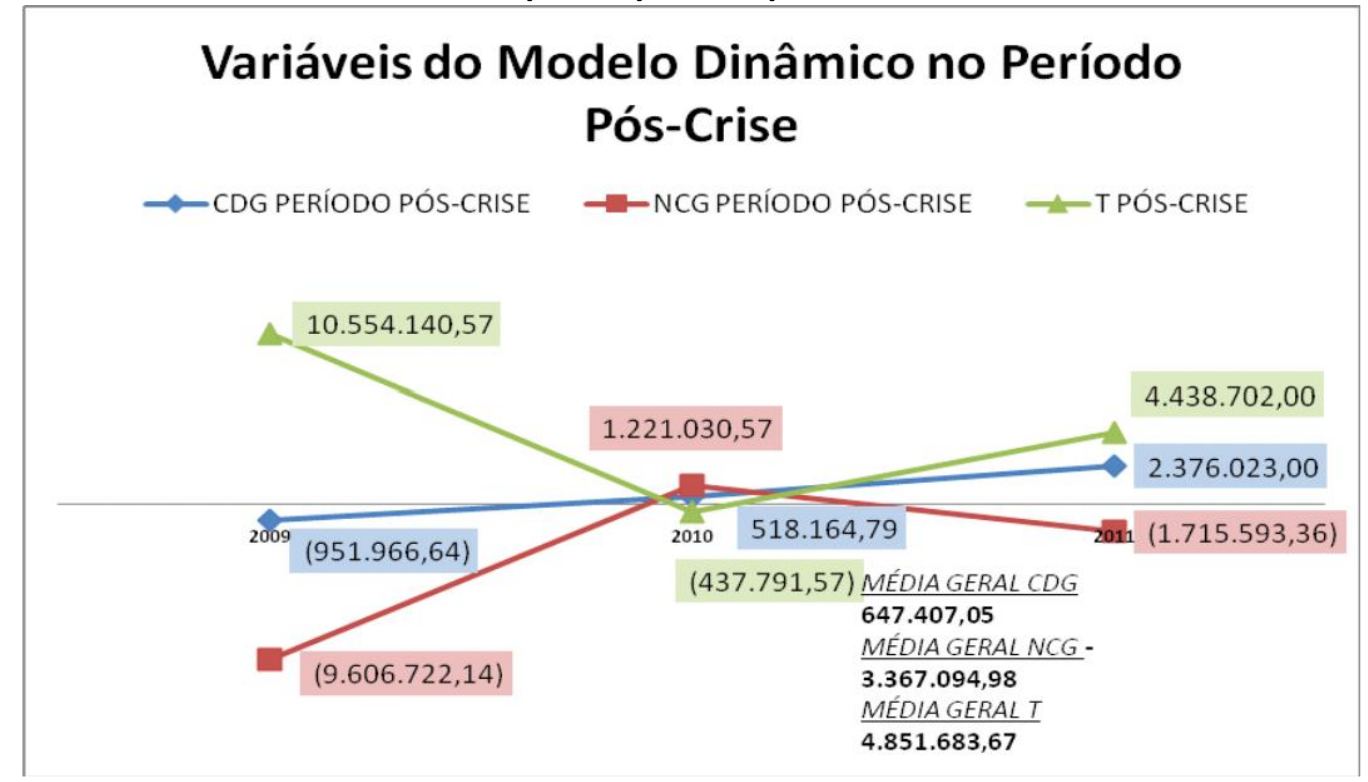

Fonte: Dados da pesquisa, 2013.

Quanto ao modelo dinâmico, apresentado na Tabela 5, percebe-se que o seu perfil passou a ser de uma empresa dita como excelente financeiramente, com CDG e ST positivos e NCG negativo. Essa situação se consolidou no ano de 2011, revelando uma tendência positiva dado que em 2009 seu perfil financeiro era dito de alto risco em 2010, insatisfatório.

Em análise ao ILD do período Pós-Crise, apresenta-se a Tabela 6.

Tabela 6 Variável ILD para o período pós-crise

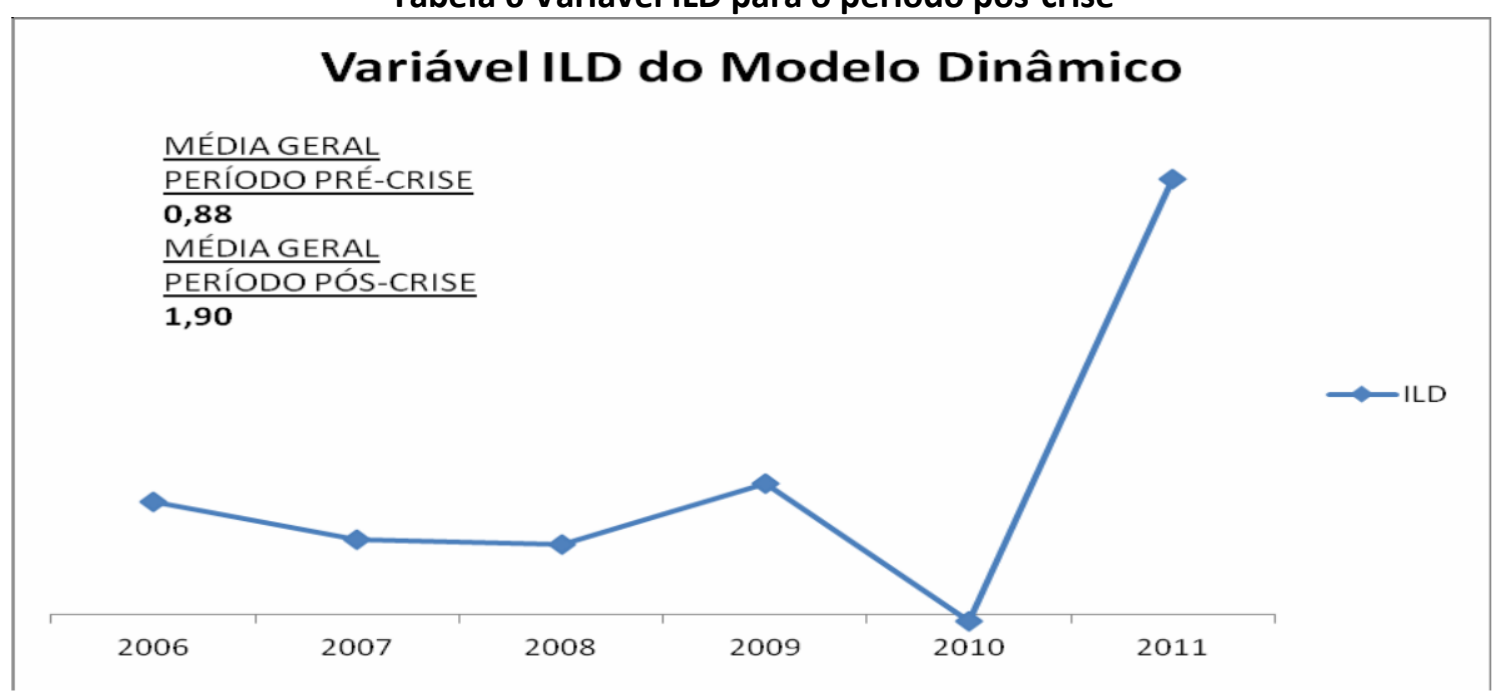

Fonte: Dados da pesquisa, 2013. 
A queda do ILD em 2010, verificada na Tabela 6, refere-se à mudança de estratégia financeira e operacional sendo que: em 2009 essa estratégia foi direcionada para Aplicações Interfinanceiras de Liquidez; em 2010, para Alavancagem em Títulos e Valores Mobiliários; e a partir de 2011, essa estratégia retornou novamente às Operações de Crédito. Essa gestão financeira também foi o motivo da retração nos índices de liquidez tradicional, representados na Tabela 4.

\section{CONCLUSÃO}

A pesquisa baseou-se em analisar a performance dos bancos brasileiros no período pré-crise e póscrise, sob a égide do desempenho dos indicadores de liquidez sob o ponto de vista do modelo tradicional e modelo Fleuriet. Assim sendo, buscou-se responder aos objetivos propostos conforme abaixo: A solidez dos bancos brasileiros se deu por meio da mudança em suas estruturar patrimoniais de forma a conter recursos financeiros nos períodos de 2006 a 2009, o que trouxe maior segurança na qualidade de liquidez operacional; Em relação à qualidade da gestão verificou-se que as empresas analisadas buscaram operações mais centradas no mercado interno, como, por exemplo, aplicações interfinanceiras de liquidez, que proporcionam maior amarração no mercado interno e flutuabilidade controlável, o que se pode observar nos dois modelos pesquisados. Portanto, o grande sucesso da pesquisa se deu em detrimento a adequação de novas perspectivas de visão financeira em um segmento que tem como matéria-prima o recurso financeiro e o gerenciamento de risco e retorno, sua atividade principal, a própria intermediação de gestão financeira operacional.

Assim, as mudanças ocorridas na gestão financeira de recursos dos bancos entre elas retração do crédito, alavancagem das aplicações interfinanceiras de liquidez e também em títulos e valores mobiliários ao longo do período analisado foram questões pontuais para a neutralizar, no mercado brasileiro, dos impactos gerados pela crise financeira mundial. Ressalta-se, entretanto, as formas efetivas de atuação do Banco Central do Brasil quanto aos aspectos regulatórios de mitigação de riscos junto do sistema financeiro nacional, proporcionando liquidez, alavancagem operacional e estrutura de capital compatível com a qualidade e quantidade adequada às necessidades exigidas pelo comportamento do mercado interno. Como pesquisas futuras poder-se-ia analisar juntamente com os indicadores pesquisados nesta pesquisa, itens como os aspectos regulatórios do Acordo da Basiléia III, no tocante à tornar o sistema financeiro com mais capacidade de adaptar às mudanças, redução dos custos de crises bancárias e maior amparo no crescimento sustentável.

\section{REFERÊNCIAS}

ANDRADE, Maria Margarida de. Como preparar trabalhos para cursos de pós-graduação: noções práticas. $7^{\circ}$ ed. São Paulo: Atlas, 2008.

ASSAF NETO, Alexandre. Administração do Capital de Giro. $4^{\circ}$ ed. São Paulo: Atlas, 2012a.

ASSAF NETO, Alexandre. Estrutura e Análise de Balanços - Um enfoque Econômico-Financeiro. 10응 ed. São Paulo: Atlas, 2012b.

ASSAF NETO, Alexandre. Finanças Corporativas e Valor. 60 edição. São Paulo: Atlas, 2012c.

BACEN. Banco Central do Brasil. Disponível em http://www.bcb.gov.br. Acesso em setembro/2013.

BEUREN, Ilse Maria. (Org.). Como Elaborar Trabalhos Monográficos em Contabilidade: teoria e prática. $3^{\circ}$ ed. São Paulo: Atlas, 2009.

BLATT, Adriano. Análise de Balanços - Estrutura e Avaliação das Demonstrações Financeiras e Contábeis. São Paulo: MAKRON Books, 2001. 
BM\&FBOVESPA - A nova Bolsa. Disponível em http://www.bmfbovespa.com.br. Acesso em setembro/2013.

BRAGA, Hugo Rocha. Demonstrações Contábeis: estrutura, análise e interpretação. 7o ed. São Paulo: Atlas, 2012.

BRASIL. PRESIDÊNCIA DA REPÚBLICA. Brasília. Lei 6.404, de 15/12/1976. Disponível em http://www.planalto.gov.br/legislacao. Acesso setembro/2013.

CAVALCANTI, F.; MISUMI, J. Y.; RUDGE, Luiz Fernando. Mercado de Capitais - O que é, como funciona. $7^{\circ}$ ed. Rio de Janeiro: Elsevier, 2009.

COSTA, L. G.; LIMEIRA, A. F.; GONÇALVES, H. M.; CARVALHO, U. T. Análise Econômico-financeira de Empresas. Rio de Janeiro: Editora FGV, 2008.

CRUZ; Paulo Giovani Da.; BRESSAN; Valéria Gama Fully. Análise Financeira de empresas: uma aplicação do modelo Fleuriet e análise da demonstração dos fluxos de caixa em empresas de Tecnologia da Informação. In: CONGRESSO USP DE CONTROLADORIA E CONTABILIDADE, 11, 2011, São Paulo. Anais... São Paulo, 2011. Disponível em http://www.congressousp.fipecafi.org. Acesso setembro/ 2013.

DELOITTE. Instituições Financeiras no Brasil. Deloitte Touche Tohmatsu, 2010.

FLEURIET, Michel; KEHDY, Ricardo; BLANC, Georges. O modelo Fleuriet - A dinâmica financeira das empresas brasileiras: um modelo de análise, orçamento e planejamento financeiro. 5o ed. Rio de Janeiro: Elsevier, 2003.

FORTUNA; Eduardo. Mercado Financeiro: Produtos e Serviços. 19o ed. Rio de Janeiro: Qualitymark, 2013.

FRANCISCO; J. R. De Souza; AMARAL; H. F.; FERNANDES, N. A. C.; DUCA; A. F.; BERTUCCI, L.A. Gestão Financeira do Segmento Bancos como Processo de Tomada de Decisão: Aplicação do Modelo Dinâmico. Revista Pensar Contábil, v. XIV, n 55, set/dez 2012, p. 41-51. Rio de Janeiro: CRCRJ, 2012.

GITMAN, Lawrence J. Princípios de administração Financeira - essencial. Tradução Jorge Ritter. 2ㅇe ed. Porto Alegre: Bookman, 2001.

IUDICIBUS, Sérgio de. Análise de Balanços, Análise da Liquidez e do Endividamento, Análise do Giro, Rentabilidade e Alavancagem Financeira. 2a edição. São Paulo: Atlas, 2013.

IUDICIBUS, Sérgio de. Análise de balanços. 10 ed. São Paulo: Atlas, 2009.

IUDICIBUS, Sérgio De; MARTINS; Eliseu; GELBCKE, Ernesto Rubens; SANTOS, Ariovaldo Dos. Manual de Contabilidade Societária. São Paulo: Atlas, 2010.

HASTINGS, David. F. Banking. São Paulo: Saraiva, 2006.

KASSAI, Silvia. Utilização da Análise por Envoltória de Dados (DEA) na Análise das Demonstrações Contábeis. Tese Doutorado. Faculdade de Economia, Administração e Contabilidade da Universidade de São Paulo, São Paulo: USP, 2002.

MACHADO, Márcio André Veras et. al. Análise e o financiamento das necessidades de capital de giro das pequenas e médias empresas. In: CONGRESSO FEA/USP CONTROLADORIA E CONTABILIDADE, 5, 2005, São Paulo. Anais... São Paulo, 2005. CD-ROM.

MARQUES, J. A. V. da Costa. Análise Financeira das empresas: liquidez, retorno e criação de valor. Rio de Janeiro: Editora UFRJ.

MATARAZZO, Dante C. Análise Financeira de Balanços. 7o ed. São Paulo: Atlas, 2010. 
MONTEIRO, A. A. S. Fluxos de Caixa e Capital de Giro: Uma Adaptação do Modelo de Fleuriet. In: EnANPAD, 27, 2003, Atibaia, Anais... Rio de Janeiro: XXVII Encontro da ANPAD, 2003, p. 1-14.

REVSINE, L., COLLINS, D. W. \& JOHNSON, W. B. Financial reporting \& analysis. Upper Saddle River: Prentice Hall, 1998.

SANTOS, Vanderlei dos; RENGEL, Silene; HEIN, Nelson. Correlações canônicas entre os indicadores tradicionais e o modelo Fleuriet na avaliação do Capital de Giro das empresas têxteis. In: CONGRESSO BRASILEIRO DE CUSTOS, 16, 2009, Fortaleza/Ceará. Anais... Fortaleza/Ceará, 2009. CD-ROM.

SANTOS, M.; SANTOS, J. O. Avaliação da Liquidez da Empresa por Métodos Alternativos: Diminuindo a Exposição ao Risco de Crédito. RIC - Revista de Informação Contábil. Recife, Vol. 2, no 2, AbrJun/2008.

SILVA, José Pereira Da. Análise Financeira das Empresas. 12e ed. São Paulo: Atlas, 2013. 